\title{
Database Biodiversity of Murmansk Region
}

\author{
Tatiana Chernenkova, Elena Basova \& Nata Koroleva
}

\begin{abstract}
The structure and composition of boreal forests in Kola Peninsula were investigated between 2005 and 2009. The objective of the research was to reveal the features of spatial distribution of forest types due to natural dynamics and as the result of industrial pollution. The total number of relevés $(25 \times 25 \mathrm{~m} 2)$ was about 350 . Using remote sensing data and data of field campaigns allowed estimating the number of species and typological diversity of north-taiga ecosystems in the Imandra lake basin. This report describes the available content in the vegetation-plot database "Database Biodiversity of Murmansk Region" (GIVD ID EU-RU-007).
\end{abstract}

Keywords: biodiversity; Kola Peninsula; Murmansk region.

\section{Database Biodiversity of Murmansk Region}

Scope: reveal the features of spatial distribution of forest types due to natural dynamics and as the result of industrial pollution

Status: completed and continuing Period: 2005-2009

Database manager(s): Tatiana Chernenkova (chernenkova50@mail.ru)

Owner: (private)

Web address: [NA]

Availability: according to a specific agreement

Database format(s): MS Access

Online upload: no

Online search: no

Publication: [NA]

Plot type(s): normal plots

Non-overlapping plots: 350

Export format(s): [NA]

Total plot observations: 350

Plot-size range: $625-625 \mathrm{~m}^{2}$

Countries: RU: $100.0 \%$

Forest: [NA] — Non-forest: [NA]

Guilds: all vascular plants: $100 \%$; bryophytes (terricolous or aquatic): $100 \%$; lichens (terricolous or aquatic): $100 \%$; algae (terricolous or aquatic): $5 \%$

Environmental data: altitude: 100\%; slope aspect: 100\%; slope inclination: $100 \%$; microrelief: $100 \%$; soil depth: 100\%; land use categories: $70 \%$ Performance measure(s): cover: $100 \%$

Geographic localisation: GPS coordinates (precision 25 m or less): $100 \%$

Sampling periods: [NA]

Information as of 2012-07-12; further details and future updates available from http://www.givd.info/ID/EU-RU-007

Tatiana Chernenkova* (chernenkova50@mail.ru), Elena Basova (lenabasova7@gmail.com), Nata Koroleva (flora12011@yandex.ru) Center for Problems of Forest Ecology and Productivity, Russian Academy of Sciences, Profsoyuznaya street, 84/32

Moscow, RUSSIA

*Corresponding author 